\title{
Dysregulation of signaling pathways associated with innate antibacterial immunity in patients with pancreatic cancer
}

\author{
ROBERT SŁOTWIŃSKI I,2, SYLWIA MAEGORZATA SŁOTWIŃSKA ${ }^{3}$ \\ ${ }^{1}$ Department of Surgical Research and Transplantology, Mossakowski Medical Research Centre, Polish Academy of Sciences, Poland \\ ${ }^{2}$ Department of Immunology, Biochemistry and Nutrition, Medical University of Warsaw, Poland \\ ${ }^{3}$ Department of Conservative Dentistry, Medical University of Warsaw, Poland
}

\begin{abstract}
Disorders of innate antibacterial response are of fundamental importance in the development of gastrointestinal cancers, including pancreatic cancer. Multi-regulatory properties of the Toll-like receptors (TLRs) (e.g., regulation of proliferation, the activity of $N F-\kappa B$, gene transcription of apoptosis proteins, regulation of angiogenesis, $H I F-1 \alpha$ protein expression) are used in experimental studies to better understand the pathogenesis of pancreatic cancer, for early diagnosis, and for more effective therapeutic intervention. There are known numerous examples of TLR agonists (e.g., TLR2/5 ligands, TLR6, TLR9) of antitumor effect. The direction of these studies is promising, but a small number of them does not allow for an accurate assessment of the impact of TLR expression disorders, proteins of these signaling pathways, or attempts to block or stimulate them, on the results of treatment of pancreatic cancer patients. It is known, however, that the expression disorders of proteins of innate antibacterial response signaling pathways occur not only in tumor tissue but also in peripheral blood leukocytes of pancreatic cancer patients (e.g., increased expression of TLR4, NOD1, TRAF6), which is one of the most important factors facilitating further tumor development. This review mainly focuses on the genetic aspects of signaling pathway disorders associated with innate antibacterial response in the pathogenesis and diagnosis of pancreatic cancer.
\end{abstract}

Key words: pancreatic cancer, Toll-like receptors, signaling pathways.

(Cent Eur J Immunol 2016; 41 (4): 404-418)

\section{Introduction}

Pancreatic cancer remains a disease of unknown pathogenesis, and despite advances in diagnosis and the treatment of cancer diseases, it still has a very poor prognosis. It occupies the fourth place as a cause of death from cancer, and the mortality rate from pancreatic cancer is similar to the number of newly detected cases and continues to grow [1-3]. Pancreatic cancer in the early stages of the disease does not give clinical symptoms, making it difficult for early diagnosis that gives hope for a successful therapy. Although there is progress being made in the knowledge on the pathogenesis of pancreatic cancer, only surgery performed in the early stages of the disease can significantly increase the survival. Unfortunately, due to the late diagnosis, only $5-6 \%$ of patients with pancreatic cancer survive five years [4-6]. At the time of diagnosis of pancreatic cancer, the tumor is unresectable in $80 \%$ of patients and there are already distant metastases; only in a few percent of patients the tumor is in the early stages of development, which in this group (for
Stage I invasive cancer with tumors $<2 \mathrm{~cm}$ in diameter) may increase the 5-year survival after surgery by $58 \%$, and in patients with tumor $<1 \mathrm{~cm}$ even to $100 \%$ [7-9]. The median survival reported for the resected pancreatic cancer ranges from 17 to 27 months and the 5-year survival is approximately $20 \%$ [10].

A previous study demonstrated that neoadjuvant therapy was associated with improved survival in resectable pancreatic adenocarcinoma, but a recent meta-analysis did not show a significant effect on overall survival among resectable patients after receiving neoadjuvant or adjuvant treatments $[11,12]$. The survival time of patients diagnosed with unresectable pancreatic tumor is on average 6 months and may increase only slightly (to 11 months) after the application of a complex chemotherapy (FOLFIRINOX), which confirms the resistance of pancreatic cancer to this type of treatment [13]. Another study reported significantly improved survival in patients with metastatic pancreatic cancer treated with gemcitabine and nab-pacl-

Correspondence: Robert Słotwiński, Department of Immunology, Biochemistry and Nutrition, Medical University of Warsaw, Oczki 3, 02-007 Warsaw, Poland, e-mail: robert_slotwinski@yahoo.com Submitted: 4.09.2016; Accepted: 16.09.2016 
itaxel compared to gemcitabine as a single therapy [14]. The median overall survival was 8.5 months in the nab-paclitaxel-gemcitabine group as compared with 6.7 months in the gemcitabine group; the survival rate was $35 \%$ in the nab-paclitaxel-gemcitabine group vs. $22 \%$ in the gemcitabine group at 1 year, and $9 \%$ vs. $4 \%$ at 2 years. It should be noted that among patients with metastatic disease, the 5 -year survival rate is only $2 \%$, and 1 -year survival rates of $17-23 \%$ with gemcitabine have been reported $[13,15,16]$.

The results of previous studies clearly indicate the need for more effective diagnostics that would enable early detection of pancreatic cancer - a highly heterogeneous disease [17]. Currently, it is difficult to expect a dramatic improvement in early diagnosis of pancreatic cancer, conducted mainly based on generally accessible, convenient, expensive and potentially invasive methods performed usually after the onset of symptoms; these include endoscopic ultrasound (EUS) and magnetic resonance imaging (MRI) of the abdomen with cholangiopancreatography or computerized tomography scan. The aforementioned methods mainly allow the assessment of the possibility of surgical treatment, but in some patients they are also helpful in identifying premalignant lesions (e.g., cystic precursor lesions) [18-20]. Problems associated with the detection of small tumors of the pancreas $(<1 \mathrm{~cm}$ in diameter), and distinguishing benign tumors from malignant, delay the surgery. However, in some cases of incorrect preoperative diagnosis of pancreatic cancer, pancreatoduodenectomy is performed in chronic pancreatitis, exposing these patients to early and late complications associated with major surgery and removal of the pancreas (30-60\% of the morbidity rate) $[21,22]$. This is supported by the fact that most large series of pancreatic resections for carcinoma show that $5-10 \%$ of cases of inflammatory mass masquerade as pancreatic carcinoma [23]. The EUS-guided fine needle aspiration (FNA) provides success rates of $90-95 \%$, as an additional diagnostic modality for diagnosis of solid pancreatic neoplasms [24]. EUS has the unique ability to obtain specimens for histopathological diagnosis, and can, therefore, play a crucial role in the evaluation of patients with inconclusive findings on initial examinations [25]. Additionally, molecular imaging techniques such as PET or MRS provide information on metabolic and signaling pathways. Considering the parametric data from these imaging approaches (anatomic, molecular, and physiological), one can better define specific tumor signatures. Such parametric characterization could provide insight into tumor metabolism, cellular density, protein expression, focal perfusion and vascular permeability of tumors [26].

As demonstrated by previous research, pancreatic ductal adenocarcinoma (PDAC) develops from the most frequent precursors, i.e., pancreatic intraepithelial lesions (pancreatic intraepithelial neoplasia - PanIN), intraductal papillary mucinous neoplasms (IPMNs), mucinous cystic neoplasms (MCNs) and the newly added intraductal tubu- lar papillary neoplasms (ITPNs) [27-31]. PanIN, IPMNs and MCNs lead to invasive PDAC by gene alterations and distant metastasis occurs late during the genetic evolution of pancreatic cancer [32, 33]. For instance, molecular changes in PanINs can be classified as "early" (KRAS2 mutations, telomere shortening, p2 $1^{\mathrm{WAF} 1 / \mathrm{CIP} 1}$ up-regulation), "intermediate" (cyclin D1 up-regulation, expression of proliferation antigens) or "late" (BRCA2 and TP53 mutations, DPC4/SMAD4/MADH4 inactivation) [32]. Studies in patients with a strong family history of pancreatic cancer revealed a correlation between multifocal neoplastic precursor lesions (PanIN) and lobular atrophy of the pancreas on EUS [34, 35]. Thus, early detection of precursor lesions of the pancreas and surgical removal should significantly improve the results of pancreatic cancer treatment. Our review is aimed at exploring the current knowledge about the pathogenesis and diagnosis of pancreatic cancer based on the genetic aspects of signaling pathway disorders associated with innate antibacterial response.

\section{Innate antibacterial signaling}

The discovery of TLRs has enabled a better understanding of disorders of the innate antibacterial response in patients with various diseases, in particular in cancer patients. Toll-like receptors are a family of pattern-recognition receptors, which play a crucial role in the activation of innate and adaptive immunity, and can be expressed in several types of cells, such as macrophages, dendritic cells (DCs), B cells, T cells, monocytes or epithelial cells $[36,37]$. TLR proteins recognize a large number of pathogen-associated molecular patterns, such as bacterial lipopolysaccharides or viral RNA. All TLRs, with the exception of TLR3, signal via the MyD88 adapter protein (myeloid differentiation factor 88) $[38,39]$. MyD88, TRAF6 (TNF- $\alpha$ receptor-associated factor 6), TRIF (Toll/IL-1-receptor domain-containing adapter inducing interferon) and TRAM (TRIF-related adaptor molecule) proteins are key molecules in the cytoplasmic signaling cascade of the antibacterial response initiated by TLRs. TRAF6 is a member of the TNF receptor-associated factor family of proteins and is an E3 ubiquitin ligase, which catalyzes the synthesis of lysine polyubiquitin chain involved in the downstream activation of NF- $\kappa \mathrm{B}$ [40]. TLR4-induced TAK1 autophosphorylation and activation require translocation of the MyD88-TRAF6-Ubcl3-cIAP-TAK1-IKK $\gamma$ signaling complex from TLR4 into the cytosol, which depends on TRAF6 and cIAPs [41]. The MyD88-dependent pathway involves the early phase of NF- $\mathrm{KB}$ activation, which leads to the production of inflammatory cytokines. The MyD88-independent pathway activates interferon (IFN)-regulatory factor (IRF3) and involves the late phase of NF- $\kappa \mathrm{B}$ activation, both of which lead to the production of IFN- $\beta$ and expression of IFN-inducible genes. TLR2 and TLR4 receptors were found to mediate the effects of HMGB1 (high mobility group box-1) in neutrophils and macrophages [42]. HMGB1 
is an important protein binding to DNA, stabilizing nucleosomes and facilitating NF- $\kappa \mathrm{B}$ activation and gene transcription [43, 44]. HMGB1 modulates the inflammatory cascade in LPS-activated macrophages by inducing the production of pro-inflammatory cytokines TNF- $\alpha$ and IL-1 $\beta$, while attenuating the release of anti-inflammatory mediators, IL-10 and TGF- $\beta 1$ [45].

TLRs might influence tumor initiation and progression through regulating the activation of transcription factors, such as NF- $\kappa \mathrm{B}$, interferon regulatory factors (IRFs) or AP-1 via mitogen-activated protein kinase (MAPKs) signaling integrators [46-50]. TLRs caused derangements in several tumor suppressor proteins (such as p16, p21, p27, p53 and $\mathrm{pRb}$ ), induced STAT3 activation and promoted epithelial-mesenchymal transition (EMT) as well as oncogene-induced senescence [51]. The abnormal expression of TLR receptors may be associated with sepsis and autoimmune diseases (lupus erythematosus, rheumatoid arthritis, type 1 diabetes) [52-56]. Interestingly, TLR receptors have been also detected in many tumor cell lines and tumors, including pancreatic ductal adenocarcinoma, whereas they are not expressed in the normal pancreatic tissue, and may be used as potential therapeutic targets [57-60]. TLRs were found to be involved in tumor cell proliferation, apoptosis and angiogenesis, while the high expression of Toll-like receptor 4/ myeloid differentiation factor 88 was correlated with poor prognosis in patients with colorectal cancer [61-65].

Most studies on pancreatic cancer refer to changes in TLR4 and TLR2 receptor signaling pathways. TLR4 was overexpressed in pancreatic cancer and TLR4 signaling via the MyD88-independent TRIF pathway modulated pancreatic carcinogenesis, because targeting TLR4 or TRIF prevented cancer progression [66]. These findings also suggest that there may be a possible participation of endogenous LPS derived from gut bacteria in modulating pancreatic carcinogenesis. LPS may act through the TLR4-MyD88NFאB signaling pathway that induces MMP-9 overexpression [67]. As reported by an earlier study, MMP-9 overexpression was related to the progression of pancreatic cancer [68]. Activation of TLR4 signaling by LPS profoundly increased the EMT of pancreatic cancer cells, and M2-polarized TAMs promoted the EMT in pancreatic cancer cells, partially through the TLR4/IL-10 signaling pathway [69]. TLR4 activation was shown to accelerate pancreatic cancer development, while MyD88 blockade using synthetic inhibitors accelerated pancreatic fibro-inflammation and carcinogenesis [70]. More specifically, this meant that MyD88 blockade resulted in an invasive pancreatic adenocarcinoma within 3 weeks in $\mathrm{p} 48 \mathrm{Cre} ; \mathrm{Kras}^{\mathrm{G} 12 \mathrm{D}}$ mice treated with caerulein compared with the development of early PanIN lesions in age-matched mice with intact MyD88 signaling. According to these finding, upon MyD88 blockage, DCs seemed to induce the formation of pancreatic antigen-restricted Th2-deviated CD4+ T cells [66]. In that study, stromal leukocytes collected from patients showed increased
TLR4 expression, and such up-regulation was also reported both in epithelial and stromal cells in KRAS-mutated mice. Interestingly, inhibition of TLR4 in these mice had a protective effect against tumorigenesis (slower tumor growth) [66]. DCs were found in large quantities in pancreatic cancer and tumor-draining lymph nodes, and the number of tumor-infiltrating $\mathrm{TH} 2$ cells inversely correlated with survival in human pancreatic cancer [71]. An in vitro study revealed that the invasive capacity of human pancreatic cancer cells was based on the TLR4-dependent NF- $\kappa B$ activation [72]. Another study correlated the level of TLR4 expression with tumor size, lymph node involvement, venous invasion and pathological stage. Patients with TLR4 overexpression had significantly shorter survival. Lipopolysaccharide (LPS) is a well-established agonist of TLR4 and could be a triggering factor in the initiation and progression of pancreatic cancer $[67,73]$. LPS, a putative ligand of TLR4, may promote tumor progression by acting directly on cancer cells and increasing the invasive ability of pancreatic cancer cells through the TLR4/MyD88 signaling pathway [72, 74]. These results also suggest that the TLR/MyD88/NF$\kappa \mathrm{B}$ signaling pathway plays a significant role in connecting inflammation with cancer invasion and progression. Moreover, silencing of TLR4 or MyD88 completely reversed the effects of LPS [72]. In contrast, the lipid A analogue (OM-174), with a dual stimulating effect on TLR2 and TLR4 receptors, induced regression of several tumor types in animal models [75-77]. Induction of MyD88 and TRIF, downstream of TLR pathways, perturbed cell cycle regulation in pancreatic cancer [70]. Other data demonstrated that protein (mRNA) expression of TLR4, NF- $\mathrm{BB}$ p65 and HIF$1 \alpha$ (hypoxia-inducible transcription factor $1 \alpha$ ) in pancreatic tumor tissues was increased by $69 \%, 66 \%$ and $70 \%$, respectively, which was significantly higher compared to adjacent normal tissues. This indicated that TLR4 might be partly involved in up-regulating HIF- $1 \alpha$, and they both could synergistically promote the development of pancreatic adenocarcinoma [58]. Another study suggested that TLR4 expression in pancreatic cancer cells was up-regulated via HIF-1 $\alpha$ in response to hypoxic stress and underscored the crucial role of HIF- $1 \alpha$-induced TLR4 in tumor growth [78]. Most studies have shown that increased expression of TLR4 is not limited to pancreatic cancer. Toll-like receptors (TLRs) are involved in the development of infectious diseases, autoimmune and neurodegenerative diseases and cancer [79]. TLR4 expression was also detected in head and neck cancer, breast cancer, lung cancer, gastric cancer, hepatocellular carcinoma, colorectal cancer, ovarian cancer, cervical cancer, prostate cancer and melanoma [58, 62]. The results of these studies indicate that the evaluation of TLR4 expression does not differentiate cancerous tumors, which makes diagnosis and treatment difficult.

Toll-like receptor 2 (TLR2) is a promising target for immune system stimulation during cancer immunotherapy and a cell-surface marker for pancreatic cancer [59]. TLR2 
stimulation may produce significant antitumor activity by enhancing the innate immunity, T-cell immunity, cytotoxic antibody function and induction of apoptosis [80-82]. Activation of immune response by synthetic lipopeptide (macrophage activating lipopeptide-2 - MALP-2), which activated TLR 2 and TLR6 receptors, resulted in a significant tumor growth reduction in a mouse model [83]. Intratumoral injection of the toll-like receptor $2 / 6$ agonist MALP-2, in a limited number of patients with pancreatic carcinoma, caused a decrease in pancreatic tumor proliferation and metastasis [84]. Another agonist of TLR2 receptor protein-bound polysaccharide-K (PSK, mushroom extract) promoted apoptosis and inhibited tumor growth in various human PDAC cell lines [85]. It was found that TLR2 receptors were highly expressed in $70 \%$ of pancreatic tumors, but their expression was low in the surrounding normal pancreas tissue; they were also found on tumor-infiltrated myeloid-derived suppressor cells (MDSC) and tumor-associated macrophages (TAM), which after activation promoted tumor expansion, invasion, and metastasis [86]. Interestingly, the disruption of TLR2-dependent antitumor pathways by pancreatic adenocarcinoma up-regulated factor (PAUF protein) could contribute to tumor persistence and facilitate tumor growth [87, 88]. Treatment with anti-recombinant human pancreatic adenocarcinoma up-regulated factor in vitro and in vivo reduced proliferation, migration, invasion, and tumorigenic capacity. These findings suggest that the new cancer-associated ligand, PAUF, may activate the TLR-mediated ERK signaling to produce the pro-tumorigenic cytokines, but it inhibits the TLR-mediated NF- $\kappa \mathrm{B}$ signaling, thereby facilitating tumor growth. More specifically, PAUF induces the extracellular signal-regulated kinase (ERK) phosphorylation and activates the IKK- $\beta$-mediated TPL2/MEK/ERK signaling pathway through TLR2 and stimulates an increased expression of protumorigenic cytokines (RANTES, MIF). In addition, PAUF was also reported to be associated with the CXC chemokine receptor (CXCR4)-TLR2 complex and to inhibit the CXCR4-dependent, TLR2-mediated NF- $\kappa \mathrm{B}$ activation. Another study showed that PAUF could induce the activation and maturation of DCs and activate NF- $\kappa$ B by stimulating the Toll-like receptor signaling pathway [89].The PAUF-mediated DC activation and immune stimulation are dependent on TLR4 and provide evidence supporting that this protein could be a promising adjuvant for DC-based therapies. The expression of PAUF was also elevated in ovarian tumors and it was found to be more frequently expressed in mucinous adenocarcinoma than in its benign and borderline counterparts, which was associated with a shorter overall survival of patients [90]. Novel high-affinity TLR2 agonists were synthesized to develop targeted agents for cancer imaging and therapy [91]. The latter study demonstrated tumor-specific retention of a fluorescently labeled agonist ligand that could potentially be used for the intraoperative detection of pancreatic can- cer cells. Vaccination with TLR2-L SLP conjugates led to the efficient induction of antitumor immunity in mice challenged with aggressive transplantable melanoma or lymphoma [92]. These data show that TLR2-L SLP conjugates are promising synthetic vaccine candidates for active immunotherapy against cancer. Therefore, most of the presented studies, which were aimed at improving the outcomes of pancreatic cancer patient treatment, were focused on the activation of TLR2 receptor signaling pathways.

Fewer studies concerned the TLR3, TLR7 and TLR9 receptors, expressed intracellularly on endosomal membranes of several types of immune cells (mainly APCs, leukocytes), e.g., macrophages, B cells and DCs [93]. These receptors recognize dinucleotides ( $\mathrm{CpG}$ motifs) found in bacteria and viruses. The activation of STAT3 and NOTCH receptors through NFKB and MAPK contribute to the aggressive tumor phenotype induced by TLR7 activation. Chimeric mice with Tlr4-/- or Tlr7-/- bone marrows were partially protected from pancreatic carcinogenesis $[19,34]$. Furthermore, TLR2, TLR7 and TLR9 were shown to be involved in the initiation of type 1 diabetes mellitus and TLR2, TLR4 played a major role in the onset of type 2 diabetes mellitus. In addition, peroxisome proliferator activated receptor- $\gamma(\operatorname{PPAR} \gamma)$, which is a nuclear receptor transcription factor implicated in the regulation of metabolism, differentiation and inflammation, was also involved in PDAC, which made it an interesting target for pharmacological prevention of PDAC in obese and diabetic patients [94]. TLR7 was found to be highly expressed both in inflammatory (in 40-65\% of the tumor microenvironment cells) and cancer cells (in 50\% of the advanced tumors) and the role of TLR7 in pancreatic cancer was also reported [51, 90]. For instance, TLR7 was reported to regulate pancreatic carcinogenesis in mice and humans, while TLR7 activation induced a loss of the p16/INK4A gene that is commonly mutated in human PDAC at a relatively early stage [51]. In that study, cancer aggressiveness induced by TLR7 agonists was associated with higher expression of cyclin B1, the c-Myc oncoprotein and the anti-apoptotic Bcl-xL protein. The decrease in cyclin D1, PTEN, p16 along with the up-regulation of several other tumor-suppressor proteins, such as p53, p21/WAF, pRB or p27/ Kip1 was also observed. Interestingly, both KRAS mutations and TLR7 stimulation are necessary for malignant transition. In addition, TLR7 ligation was shown to induce STAT3 activation and interfere with Notch as well as canonical NF- $\kappa \mathrm{B}$ and MAP kinase pathways, but the down-regulated expression of Notch target genes and blockade of TLR7 protected against carcinogenesis.Furthermore, mice lacking TLR7 exclusively in their inflammatory cells were protected from neoplasia.The therapeutic mechanism of TLR7 agonist (Imiquimod) was associated with the activation of immune cells involved in an effective antitumor immune response - B lymphocytes, plasma cells, NK and Langerhans cells [95]. Treatment with imiquimod down-regulated 
MHC class I molecules on tumor cells and these results indicated that the stimulation of tumor cells with TLR3 or TLR7 ligands enhanced the cytotoxic activity of $\gamma \delta$ T cells of cancer patients in vitro [96]. As recently presented in the PDAC cell line, the enhanced Cox-2 expression and increased release of the Cox-2 metabolite, prostaglandin E2 (PGE2), promoted resistance against $\gamma \delta$ T cell-mediated lysis; in addition, the application of tribody $\left[(\mathrm{Her} 2)_{2}\right.$ $\times \mathrm{V} \gamma 9$ ] that enhances $\gamma \delta$ T-cell cytotoxicity, and Cox -2 inhibitors that overcome the PGE2-mediated resistance of PDAC cells to the cytotoxic activity of $\gamma \delta$ T cells, might offer a promising combined immunotherapy for pancreatic cancer [97]. A recent study demonstrated that TLR7 and TLR8 were highly expressed by the primary human ductal pancreatic cancer and TLR7/TLR8 expression increased tumor growth in vivo [98]. Stimulation of PANC1 cells overexpressing TLR7/TLR8 resulted in elevated NF- $\kappa \mathrm{B}$ and COX-2 expression, increased cancer cell proliferation and reduced chemosensitivity. These data demonstrate stage-dependent up-regulation of both TLR7 and TLR8 expression in pancreatic cancer.

Recently, TLR9 was linked both to acute pancreatitis and cancer [99]. TLR9 was shown to signal through the MyD88-dependent pathway, leading to the production of pro-inflammatory cytokines, but the participation of TLR9 is better known in acute pancreatitis than in pancreatic cancer [100]. The expression of TLR9 was shown to be more pronounced in pancreatic cancer tissue and the TLR9 gene was found to be correlated with the invasive and metastatic potential of human pancreatic carcinoma [101]. The percentage of positive cells expressing TLR9 protein in human pancreatic tissues, paracancerous tissues and normal tissues was $73.3 \%, 33.3 \%$ and $20.0 \%$, respectively. In acute pancreatitis, a similar pattern of staining in exocrine pancreas was reported for TLR4 [102]. On the other hand, TLR2/4/9 agonists seemed to be good candidate molecules prolonging survival in patients with different types of cancer by inducing the expression of tumor necrosis factor $\alpha$ (TNF- $\alpha$ ) and inducible nitric oxide synthase (iNOS) that activate dendritic cell trafficking and its associated tumor-specific cytotoxic T-cell responses [103-106]. Evaluation of the efficacy of the ISCOM (immune stimulatory complexes)vaccine in a murine pancreatic carcinoma model revealed that the ISCOM vaccine effectively induced Ag-specific CTL capable of killing tumor cells, but did not affect tumor growth, and this lack of efficacy was correlated with increased numbers of Treg [107]. It should be emphasized that when the authors of the latter study depleted Treg with anti-CD25 mAb, CTL induction and prolonged survival was restored, and adding a lowdose of $\mathrm{CpG}$ to the ISCOM vaccine reduced the number of Treg, enhanced CTL responses and initiated regression of pancreatic tumors in a CD8(+) T cell-dependent manner. Interestingly, concomitant gemcitabine therapy negatively affected DC vaccine-induced CD8(+) T-cell and B-cell responses, but improved clinical efficacy in a murine pancreatic carcinoma model [108]. Despite the reduced number of tumor-reactive T-cells in peripheral blood, in vivo cytotoxicity assays revealed that the cytotoxic T-cell (CTL)-mediated killing was preserved. Another study showed that immunomodulatory oligonucleotide (IMO), TLR9 agonist, interfered with EGFR-dependent signaling (overexpressed in 50-60\% of human pancreatic adenocarcinoma), modulating the functional interaction between TLR9 and EGFR, and markedly inhibited the growth of K-Ras mutant colon and pancreatic cancers in vitro [109, 110]. Furthermore, IMO and cetuximab combination caused a potent and long-lasting cooperative antitumor activity in colorectal cancer and in orthotopic pancreatic cancer models in vivo. In an orthotopic mouse model of a human pancreatic tumor xenograf, the antitumor chemotherapy effects (gemcitabine) were combined with the potent TLR9 synthetic agonists (CpG-oligodeoxynucleotides) [111]. These studies showed that the tumor spread in the peritoneal cavity was reduced to a greater extent in combined therapy than with gemcitabine alone, and it significantly improved the survival time.

Considering the fact that the body of evidence is still limited, it is impossible to conclude whether TLR3 and TLR9 play an important role in patients with pancreatic cancer. Similarly as TLR2 and TLR4, TLR3 is expressed in various tumors, including colorectal, ovarian, breast, hepatocellular, laryngeal cancer and melanoma [112-115]. The TLR3 gene codes for an endoplasmic receptor of the pattern-recognition receptors (PRRs) family that recognizes double-stranded RNA (dsRNA) and plays an important role in the innate immune response triggered by viral infection. Several studies demonstrated that activation of TLR3 by dsRNA directly inhibited cell proliferation and induced apoptosis in tumor cells [116-118]. Synthetic dsRNAs (e.g., polyinosine-cytosine, poly I:C; polyadenylic-polyuridylic, poly A:U) were demonstrated to be one of the agents in tumor chemotherapy demonstrating favorable outcome in clinical trials [119]. TLR3 agonist (polycytidylic acid) was found to induce lysis of pancreatic cancer cell lines by enhancing the cytotoxic activity of $\gamma \delta \mathrm{T}$ cells in vitro, but this agonist could also acceleratepancreatic carcinogenesis in KRAS-mutated mice [96]. The presence of constitutively activated TLR3/Wnt5a expression in human pancreatic cancer and malignant melanoma cell lines was decreased by phenylmethimazole, which in turn inhibited the growth and migration in both of these cancer cell lines [120]. In colon carcinoma, cell line anticancer drugs (e.g., 5-FU) increased the TLR3 expression and intensified the poly I:C-induced apoptosis via p53-dependent and -independent pathways [121]. The results of other studies suggested that IFN- $\alpha$ enhanced TLR3-mediated antiviral cytokine expression in human endothelial and epithelial cells by up-regulating TLR3 expression [122]. Recent data indicated that mucin1 cytoplasmic tail (MUC1-CT), a neg- 
ative regulator of TLR inflammatory signaling mediated through the MyD88 adaptor protein, was able to counter-regulate the apoptotic and inflammatory responses of airway epithelial cells through the constitutive association with TLR3, thereby inhibiting poly(I:C)-induced recruitment of TRIF to TLR3 [123]. MUC1 is a membrane-tethered mucin glycoprotein expressed on the apical surface of mucosal epithelial cells and was originally cloned in pancreatic cancer cells [124]. Aberrantly glycosylated MUC1 - an oncogenic molecule - is overexpressed in most human epithelial cancers [125]. Overexpression of MUC1 in cancer is caused by the increased gene dosage and the level of transcription, as well as by the loss of post-transcriptional regulation [126]; MUC1 overexpression leads to metastasis and poor prognosis in pancreas cancer patients [127]. Importantly, by targeting the EGF receptor(s), the STAT1 axis attenuates tumor growth and metastasis through down-regulation of the MUC4 mucin in human pancreatic cancer [128]. In those studies, canertinib or afatinib therapy resulted in a reduction of MUC4 (MUC4 mucin de novo expression occurs in 70-90\% of pancreatic cancer patients)and abrogation of in vitro and in vivo oncogenic functions of MUC4 in pancreatic cancer cells. Furthermore, canertinib and afatinib treatment also inhibited the proliferation, migration and survival of pancreatic cancer cells by attenuating signaling molecules, including pERK1/2 (T202/Y204), cyclin D1, cyclin A, pFAK (Y925) and pAKT (Ser473). Unfortunately, the low level of serum MUC4 limits its diagnostic/prognostic potential, however, the present data open a new range of therapeutic applications for TLR3 agonists as cytotoxic agents and for efficient drug delivery in selected cancers with specific tumor markers.

Research aimed to elucidate the mechanisms underlying the development of pancreatic cancer drew attention also to other innate immunity receptors/protein signaling pathways. It has been shown that bacterial flagellin is a natural ligand of TLR5 receptor, which is also an attractive candidate for therapeutic targeting in cancer [129]. Bacterial flagellin and flagellin-expressing bacteria (Salmonella) exhibited antitumor effects in mouse models of colon and liver metastasis of pancreatic cancer, although these effects required TLR 5 expression by the tumor cells and production of cytokines (G-CSF, IL-6, IL-8, and IL-10) by cells recruited to the tumor $[130,131]$. The results of a recent study have defined the liver as a key mediator of TLR5-dependent effects in vivo and suggested clinical applications for TLR5 agonists as hepatoprotective and antimetastatic agents [132]. In a mouse xenograft model of human breast and colon cancer cells, TLR5 activation by flagellin mediated innate immune response induced a potent antitumor activity that suppressed cell proliferation and inhibited tumor growth [133, 134]. In addition, it was shown that TLR5 was also highly expressed on gastric carcinoma cells [135], and those authors found that the expression of TLRs
(TLR4, TLR5, TLR9) enabled gastric carcinoma cells to interact with $H$. pylori. Moreover, other findings suggest that genetic polymorphisms in TLR2 and TLR5 may play important roles in the process of $H$. pylori-related gastric carcinogenesis [136]. To date, the specific function and detailed mechanism of TLR5 signaling pathways in the development of pancreatic cancer are still unknown.

Among the genes involved in innate antibacterial signaling pathways that affect the development of pancreatic cancer, HMGB1 and TRAF6 are important in the regulation of the local inflammatory response. HMGB1 is one of the most characteristic genes deregulated in solid tumor tissue and serum, including pancreatic cancer [137, 138]. Studies in cell lines showed that HMGB1 was strongly up-regulated in breast cancer, colon cancer, melanoma, pancreatic cancer and prostate cancer; up-regulated HMGB 1 activated TLR2 and TLR4 expressed on immune cells and induced cancer progression and metastasis [139]. Moreover, HMGB1 and S100A9 - two DAMPs that bind TLR4 - were detected in the pancreas of PDAC patients [66]. The serum level of HMGB1 showed a tendency to increase with the progression of gastric and pancreatic cancers and is considered a powerful diagnostic biomarker for pancreatic ductal adenocarcinoma [137, 140]. HMGB1 overexpression was associated with tumor progression and poor prognosis in pancreatic cancer and was an independent prognostic indicator for patients' survival [141]. Overexpression of HMGB1/RAGE (receptor for advanced glycation end products) was associated with reduced apoptosis and prolonged cancer cell survival [142]. The HMGB1/RAGE inflammatory pathway was demonstrated to promote pancreatic tumor growth by regulating mitochondrial bioenergetics [143]. The lack of RAGE, or inhibition of HMGB1 release, diminished the production of ATP and slowed tumor growth in vitro and in vivo. An experimental study showed that TRAF6 (TNF receptor-associated factor 6) acted as an oncogene, which was important for RAS-mediated oncogenesis and provided a mechanistic explanation for the already apparent importance of constitutive NF- $\kappa \mathrm{B}$ activation in the RAS-driven lung cancer [144]. The nuclear transcription factor- $\kappa \mathrm{B}$ RelA was also found to be constitutively activated in human pancreatic adenocarcinoma cells [145]. The participation of the TRAF6 gene in the pathogenesis and progression of pancreatic cancer is not clear. Tumor necrosis factor receptor-associated factor 6 is an adapter protein involved in the activation of the TLR-mediated nuclear factor- $\kappa \mathrm{B}(\mathrm{NF}-\kappa \mathrm{B})$ signaling pathway that induces the production of pro-inflammatory cytokines. TRAF6 as a part of signaling complex (MyD88-IRAK4-IRAK1-TRAF6) is required for the pro-inflammatory cytokine production induced by TLR7 and TLR9 signaling. TRAF6 was shown to up-regulate the expression of hypoxia-inducible factor (HIF-1 $\alpha$ ) and promote tumor angiogenesis [146]. However, it was demonstrated that poor vascularization was a characteristic feature 
of pancreatic cancer [147]. The expression of TRAF6 was up-regulated in pancreatic cancer tissues and over-expression of TRAF6 in pancreatic cancer cells promoted cell proliferation and migration, whereas down-regulation of TRAF6 impaired the tumorigenicity of pancreatic cancer cells in vitro and in vivo [148]. These results suggested that TRAF6 might represent a potential therapeutic target. In an orthotopic xenograft model of SCID mice, a combination of proteasome inhibitor (MG132) and ionizing radiation therapy resulted in a significant increase in the tumor growth delay and a decreased tumor tissue expression of TRAF6 [149]. Additionally, we have recently proposed that overexpression of TLR4, NOD1 and TRAF6 genes and lower MyD88 gene expression in peripheral blood leukocytes of patients with pancreatic cancer, could contribute to chronic inflammation and tumor progression by the up-regulation of the innate antibacterial response (e.g., to LPS) [150]. Although the evidence suggesting carcinogenic and therapeutic effects of stimulation or inhibition of TLRs is increasingly growing, it still remains unclear what kind of changes in gene expression of the TLR signaling pathways in leukocytes are associated with pancreatic cancer.

The results of our study clearly indicated an abnormal gene expression in the innate antibacterial signaling pathways in peripheral blood leukocytes of patients with pancreatic cancer, which might lead to leukocyte dysfunction. We postulate that the pathologic gene expression of receptors and proteins regulating the innate antibacterial response to various stimuli must be primarily included in the analysis of a multistep sequence of events leading to the development and progression of pancreatic cancer. In our opinion, the adjuvant therapy of pancreatic cancer should also focus on the regulation of gene expression in peripheral blood leukocytes. Hypothetically, the influx and recruitment of leukocytes to the tumor microenvironment with the formation of inflammatory infiltration may facilitate cancer cell escape from the control of the immune system in poorly defined mechanisms, for instance, chronic inflammation and immune suppression in the tumor microenvironment with immune responses mediated by Treg, dendritic cells, MDSCs (myeloid-derived suppressor cells) and Th17 cells, MMPs-matrix metalloproteinases and HIF- $\alpha$-hypoxia-inducible transcription factor overexpression or increased production of IL-10 and $\mathrm{H}_{2} \mathrm{O}_{2}$. Changing the microenvironment of the tumor cells by regulating the expression of genes encoding proteins of the innate antibacterial signaling pathway (e.g., using immunonutrition) in leukocytes infiltrating the tumor cells is a novel therapeutic approach (Fig. 1). This applies to both the main tumor mass, which cannot always be removed surgically, and micrometastases that are beyond the reach of diagnostic tests. Furthermore, the assessment of the gene expression profile in leukocytes can be useful for monitoring the course of disease and genetic effectiveness of the treatment. Our previous study in a small group of malnour- ished pancreatic cancer patients with overexpression of the TLR4 gene in peripheral blood leukocytes revealed that enteral supplementation of glutamine (diet consisting of 20 g glutamine per day) could decrease TLR4 expression within five days prior to surgery [151]. This surprising effect of immunonutrition in pancreatic cancer patients could be associated with a decrease in the amount of stimulants reaching the TLR4 receptor (e.g., by blocking LPS or DAMPs - damage-associated molecular pattern molecules, interacting with TLR4 receptor). An experimental study showed that enteral administration of glutamine reduced the elevated expression of TLR4, signal adaptor protein MyD88 and TRAF6 mRNA in the intestinal mucosa in response to LPS-induced endotoxemia in rats [152]. Investigations on the effect of this treatment on the number of infectious complications and course of the disease are in progress. It is also known that fatty acids (omega-3) can have a selective inhibitory effect on the signaling cascade related to the innate antibacterial response by blocking the interaction of endotoxin with the TLR4 receptor and intracellular signaling proteins [153]. Similar studies in patients with pancreatic cancer have not been performed, but it is well recognized that glutamine is an important fuel (nitrogen donor in nucleotide and amino acid biosynthesis) for the growth of tumor cells. Other studies suggested that inhibiting LPS-induced TLR4 signaling (e.g., by Eritoran/ E5564, TLR4 small molecule antagonist) could improve therapeutic outcomes by preventing cancer metastasis during the perioperative period of colorectal cancer resection [154]. Using a unique ability of pancreatic cells to accumulate omega- 3 fatty acids, EPA and DHA were found to induce ROS accumulation and caspase-8-dependent cell death in human pancreatic cancer cells (MIA-PaCa-2 and Capan-2) in vitro [155]. Previous studies demonstrated that EPA inhibited the proliferation of all human pancreatic cancer cell lines in a dose-dependent fashion, and apoptosis was found to be associated with the activation of caspase-3 and suppression of cyclo-oxygenase- 2 expression [156]. Polyunsaturated fatty acids (PUFAs) induced apoptosis also in normal gastric and gastric carcinoma cells [157]. Most studies showed that PUFAs caused selective cytotoxicity towards cancer cells via apoptosis, little or no toxicity to normal cells and potentially increased the sensitivity of tumor cells to conventional therapies [158]. A promising phase III trial demonstrated that intravenous $\omega-3$ FAs in combination with gemcitabine improved the activity and quality of life (QOL) in patients with advanced pancreatic cancer [159]. Moreover, the TLR4 protein and mRNA level were markedly down-regulated by PUFA $1: 1$ compared with SFA, however, rats fed the PUFA $1: 4$ diet failed to exhibit these changes [160]. These data highlight the role of the PUFA $1: 1$ diet in the prevention of obesity and related metabolic disorders by suppressing the activation of TLR4, a critical modulator of pro-inflammatory cytokines. An additional nutritional therapy reducing the 


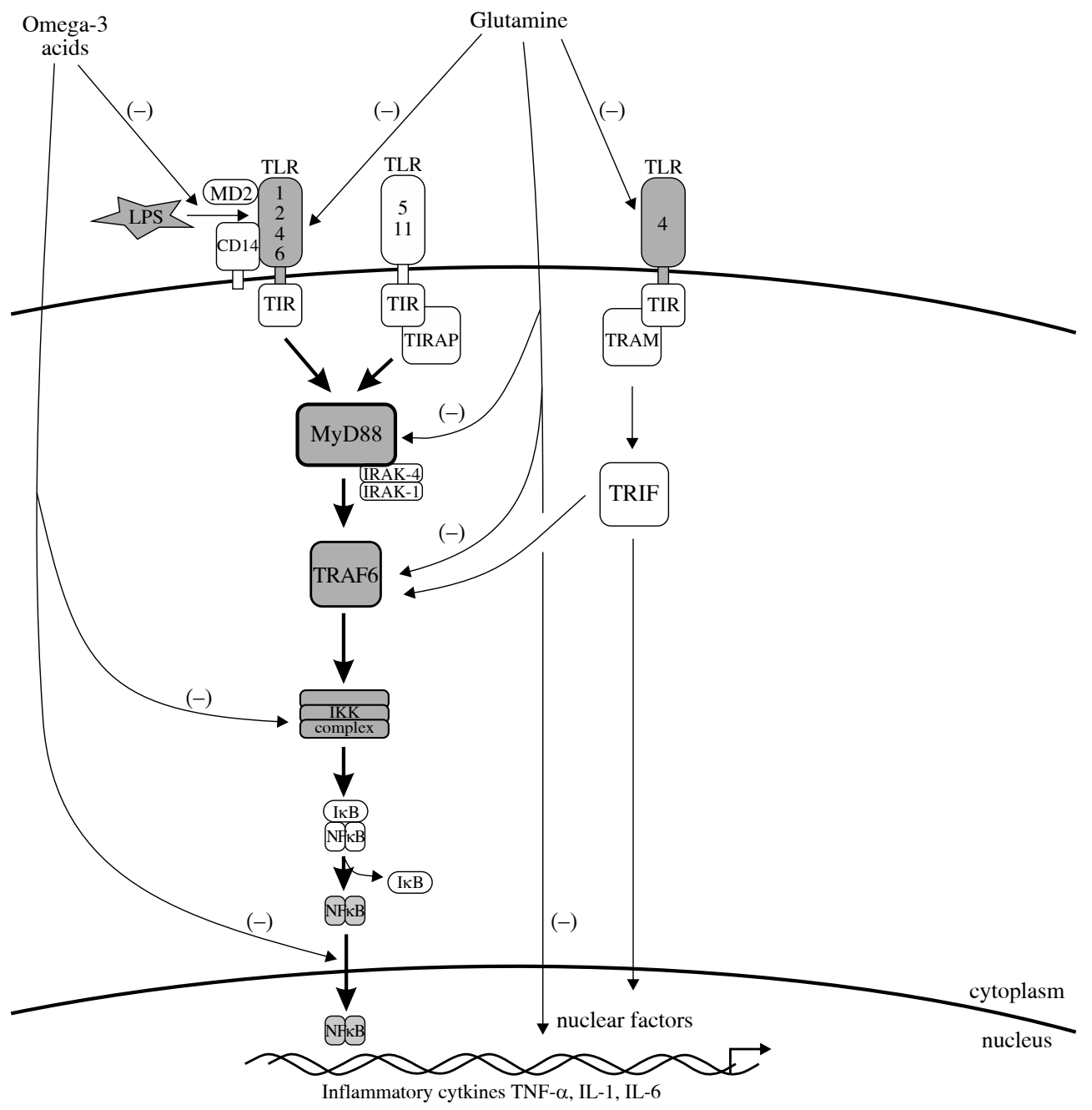

TLR - Toll-like receptor; TIR - Toll-IL-1 receptor; TIRAP - TIR-domain-containing adapter protein; TRAM - TRIF-related adapter molecule; TRIF - Toll/IL-1-receptor domain-containing adapter inducing IFN; MyD88 - myeloid differentiation factor 88; TRAF6 - TNF- $\alpha$ receptor-associated factor 6; IKK - inhibitory $\kappa B$ kinases complex; $N F-\kappa B-$ nuclear factor $\kappa B ; T N F-\alpha-$ tumor necrosis factor $\alpha$; IL-1 - interleukin 1; IL-6 - interleukin 6; LPS - lipopolysaccharide

Fig. 1. Schematic diagram of TLR4, MyD88 and TRAF6 down-regulation following glutamine administration in LPS-stimulated peripheral blood leukocytes of pancreatic cancer patients. N-3 PUFAs inhibition of TLR signaling pathway at the extracellular (DHA interfere with TLR4 receptor) and intracellular level: inhibition of the phosphorylation and degradation of the $\mathrm{I} \kappa \mathrm{B}$, inhibition of the NF- $\kappa \mathrm{B}$ activation and inflammatory cytokines production

expression of TLR4 on tumor cells would probably also inhibit its growth and local inflammation in patients with pancreatic cancer, but these mechanisms are not fully understood. A better known mechanism of omega-3 fatty acid action applies to their pro-apoptotic and anti-inflammatory activity on tumor cells (e.g., regulation of Bcl-2, Bax and c-Myc, and effects on lipids metabolism) [161-163]. Tissue samples derived from patients with head and neck, esophageal, gastric, colorectal, liver, pancreatic, skin, breast, ovarian, cervical, and breast cancer were shown to express increased amounts of TLR4 [164], indicating that modulation of the TLR4 signaling pathway would have a beneficial effect on most common cancers.

Apart from TLRs, a significant role in the recognition of pathogen-related molecular patterns and regulation of the innate antibacterial response is also played by other proteins belonging to the pathogen-associated molecular pattern (PAMP) receptors, including peptidoglycan recognition proteins, cytosolic NOD (nucleotide-binding oligomerization domain) proteins and TREM1 receptor (triggering receptor expressed on myeloid cells 1) [165]. Both TLR and NLR pathways are mediated through different adap- 
tor proteins, but they are commonly found to activate the $\mathrm{NF}-\kappa \mathrm{B}$, which induces the expression of proinflammatory cytokines [166]. The nucleotide-binding oligomerization domain is expressed in a wide variety of cell types of both hematopoietic and non-hematopoietic origin. Proteins with this domain (e.g., NLRs - NOD-like receptors: NOD1, NOD2) possess the ability to bind LPS and bacterial peptidoglycan; they can also transmit a signal independently of TLRs, which also results in NF- $\kappa \mathrm{B}$ activation and stimulation of the expression of cytokine-coding genes (for NOD1: TNF- $\alpha$ and IL-6, and for NOD2: TNF- $\alpha$ and IL$1 \beta)$ and adhesive molecules [167]. NOD1 recognizes the compounds (meso-diaminopimelic acid with peptidoglycan) of Gram-negative and some Gram-positive bacteria [168], whereas muramyl dipeptide is the ligand for NOD2, derived from the wall of Gram-positive and Gram-negative bacteria [169, 170]. NOD-like signaling is involved in the regulation of immune homeostasis in the gut. NOD2 deficiency in mice could lead to a compromised epithelial barrier and impaired immune response to commensal microbiota [171]. In turn, NOD1 deficiency resulted in increased tumor formation associated with the inflammation of the colon in mice [172]. NOD1 and NOD2 are involved in the pathogenesis of diabetes, presumably through the recognition of the gut microbiota [173]. It was reported that a NOD2 gene mutation might be also a predisposing factor for colorectal cancer characterized by a higher average age of disease onset in subjects who do not harbor any other genetic predisposition to the disease [174]. Polymorphisms in NOD1/CARD4 and NOD2/CARD15 genes may shift the balance between pro- and anti-inflammatory cytokines, thereby modulating the risk of infection, chronic inflammation and cancer [175]. NOD1/CARD4 and NOD2/CARD15 gene polymorphisms may be associated with altered risk of gastric, colorectal, breast, ovarian, prostate, testicular, lung, laryngeal, liver, gallbladder, biliary tract, pancreatic, small bowel, kidney, urinary bladder and skin cancer as well as non-thyroid endocrine tumors, lymphoma and leukemia. In another meta-analysis, NOD2 rs2066844 C/T, rs2066845 C/G and rs2066847 (3020insC) polymorphisms were potentially associated with an increased cancer risk; moreover, in the cancer type subgroup analysis, the insC/ insC+ins $\mathrm{C} / 2$ genotype was significantly associated with an increased risk of colorectal cancer, gastric cancer, MALT lymphoma, breast cancer, lung cancer and laryngeal cancer, but not with urogenital cancer, pancreatic cancer, melanoma and non-Hodgkin lymphoma [176]. Furthermore, signaling pathway analyses in a genome-wide association study (data from 3,851 pancreatic cancer cases) revealed that the NOD1 gene was associated with the risk of pancreatic cancer (H. pylori - cytokine signaling pathway) [177]. Further, large-scale and well-designed studies are still needed to confirm the relationship between the NOD gene expression and the risk of pancreatic cancer.

\section{Conclusions and future directions}

The results of the studies on the various markers in peripheral blood are strongly affected, i.a., by local disorders of the innate and acquired immune response. Increased expression of biomarkers in peripheral blood reflects a variety of metabolic/immune/genetic disorders associated with both host and tumor defence reactions. These disorders are conducive to the "escape" of cancer cells out of control of the immune system, they inhibit the response to cancer cells and enhance the status of tolerance/immunosuppression. Of significant importance in this process is simultaneously increasing lack of energy substrates, hypoxia of the pancreas tumor tissue caused by poor vascularization and increasing tumor activity accompanied by changes in the number and activity of tumor-infiltrating cell. Most frequently, local change of immunity includes: lymphocyte/neutrophil ratio, changes in subpopulations of T cells (Treg, Tc, Th1/Th2, CD8+, CD45RO+ density), dendritic cells, myeloid suppressor cells (MDSC), M1/M2 macrophages, growth factors (e.g., EGF, FGF, VEGF) or cytokines (e.g. IL-5, 6, 10, 13); these changes are not specific to pancreatic cancer, as they are also found in other gastrointestinal tract cancers [178181]. In pancreatic cancer patients, local cellular immunity disorders (e.g., high or low lymphocyte density in cancer infiltration) have a significant impact on survival [178]. On the other hand, studies of cellular immunity disorders in the peripheral blood showed that MDSCs and Tregs were statistically significantly elevated in pancreatic, esophageal and gastric cancer compared with controls. Moreover, elevated MDSC percentage was associated with an increased risk of death, while in a multivariate analysis, MDSC level was an independent prognostic factor for survival [179]. These studies highlighted basic mechanisms inhibiting or promoting tumor growth, with particular emphasis on their practical diagnostic and therapeutic significance.

As demonstrated by the presented works, in order to increase the effectiveness of methods for early detection of disorders leading to the development of pancreatic cancer, first of all, the knowledge of the local mechanisms regulating signaling pathways associated with innate antibacterial response should be broadened. It should be emphasized that disorders of innate antibacterial response are of fundamental importance in the development of gastrointestinal cancers, including pancreatic cancer. In interpreting the results of disorders of the innate antibacterial immunity mechanisms, the nutritional status of patients and peripheral cellular immunity disorders (e.g., lymphocyte-related apoptosis) should also be taken into account. Previously cited research results indicate that the number of lymphocytes in tumor infiltration (especially the density of tumor infiltrating effector cells) is reduced compared to neutrophils, which is of important prognostic significance. In most studies, the problem of nutritional status disorders of patients (lack of nutritional substances for the proper 
functioning of the immune system) is omitted, although it is known that malnutrition is an inherent factor associated with gastrointestinal tract cancers worsening the prognosis. Nutritional deficiencies should be compensated in these patients by appropriate nutritional therapy, which may have a beneficial effect on changing the tumor environment and cancer cells' metabolism. Metabolic reprogramming is linked to the activation of oncogenes but also to the inhibition of tumor suppressor genes [182]. Interestingly, human pancreatic ductal adenocarcinoma cells rely on a different metabolic pathway than normal pancreatic cells, and, for example in cancer cells, glutamine-derived aspartate is transported into the cytoplasm where it can be converted into oxaloacetate by aspartate transaminase [183]. Furthermore, these studies show that the reprogramming of glutamine metabolism is mediated by oncogenic KRAS, the signature genetic alteration in PDAC, through the transcriptional upregulation and repression of key metabolic enzymes in this pathway. In a recent study, targeting the glutamine metabolism sensitized pancreatic cancer to the PARP-driven metabolic catastrophe induced by $\beta$-lapachone, which is an NADPH: quinone oxidoreductase (NQO1)-bioactivatable drug that leads to NADPH depletion (NQO1 expression is highly activated by mutant KRAS signaling) [184]. It should also be noted that in comparison to other cells, pancreatic cancer cells have a unique property of polyunsaturated fatty acid (omega-3) accumulation, which allows to induce apoptosis in them [185]. Additionally, these data also suggest that treating pancreatic cancer cells with omega-3 fatty acid alone, or in combination with gemcitabine, result in an increased inhibition of proliferation, and the mechanism of this inhibition is related to apoptosis progression.

Dysregulation of signaling pathways associated with innate antibacterial immunity is important factor playing a crucial role in pathogenesis, development, prognosis and therapy of pancreatic cancer. The increased interest in this line of research stems mainly from an elevated expression of TLRs and signaling pathway proteins associated with these receptors in pancreatic cancer cells when compared with healthy pancreatic gland. The most interesting are multi-regulatory properties of the TLR receptors (e.g., regulation of proliferation, the activity of $\mathrm{NF}-\kappa \mathrm{B}$, gene transcription of apoptosis proteins, regulation of angiogenesis, HIF-1 $\alpha$ protein expression) used in experimental studies to better understand the pathogenesis of pancreatic cancer (assessment of bacterial factor participation) and the possibility of therapeutic intervention. This is supported by a number of examples of agonists discussed here (e.g., TLR2/5 ligands, TLR6, TLR9) exhibiting antitumor activity, although parallel stimulation of other TLRs (TLR7/TLR8) produced the opposite effect, while reducing the sensitivity of the tumor to chemotherapy. On the other hand, it appeared that blocking selected TLRs (TLR4, TLR7) could inhibit the development of mouse and human pancreatic cancer cells, while inhibiting the MyD88 signaling pathway in dendritic tumor-infiltrating cells paradoxically stimulated the development of pancreatic cancer. The direction of these studies is promising, but the small number of them does not allow for an accurate assessment of the impact of expression disorders of TLRs, proteins of these signaling pathways, or attempts to block or stimulate them, on the results of treatment of pancreatic cancer patients. It is still difficult to determine whether these disorders may precede the development of pancreatic cancer or whether the discussed parameters can be used as early markers. It is known, however, that the expression disorders of proteins of innate antibacterial response signaling pathways occur not only in tumor tissue but also in peripheral blood leukocytes of pancreatic cancer patients (e.g., increased expression of TLR4, NOD1, TRAF6), which is one of the most important factors facilitating further tumor development.

New hopes for the improvement of pancreatic cancer treatment are associated with genetic testing of microRNA expression changes, the aim of which is to better understand the pathogenesis as well as diagnostic and therapeutic possibilities. MicroRNAs are small non-coding RNAs (19-24 nucleotides long) that regulate gene expression by affecting translation of messenger RNA. MicroRNAs are aberrantly expressed in many tumors and elicit oncogenic or tumor-suppressive functions. Importantly for cancer diagnosis and better understanding of their pathogenesis, altered expression of microRNAs can be determined in the serum and tumor tissues, including paraffin sections. Similarly to investigating cell infiltrations of pancreatic tumor, the assessment of changes in the expression of microRNAs can be a valuable complement to the routine tests (e.g., immunohistochemistry). MicroRNAs mediate signaling network of apoptosis pathways and down-regulation of mutationally activated oncogenic KRAS and its downstream signaling pathways in PDAC [186]. A large body of evidence has revealed dysregulation of miRNAs in PDAC, IPMN and PanIN lesions, suggesting their use as biomarkers for early diagnosis of pancreatic cancer.

The authors declare no conflict of interest.

\section{References}

1. Siegel RL, Miller KD, Jemal A (2015): Cancer statistics. CA Cancer J Clin 65: 5-29.

2. Siegel R, Ma J, Zou Z, Jemal A (2014): Cancer statistics. CA Cancer J Clin 64: 9-29.

3. Raimondi S, Maisonneuve P, Lowenfels AB (2009): Epidemiology of pancreatic cancer: an overview. Nat Rev Gastroenterol Hepatol 6: 699-708.

4. Jemal A, Siegiel R, Xu J, Ward E (2010): Cancer statistics. CA Cancer J Clin 60: 277-300.

5. Bosetti C, Bertuccio P, Negri E, et al. (2012): Pancreatic cancer: overview of descriptive epidemiology. Mol Carcinog 51: 3-13. 
6. Bosetti C, Bertuccio P, Malvezzi M, et al. (2013): Cancer mortality in Europe, 2005-2009, and an overview of trends since 1980. Ann Oncol 24: 2657-2671.

7. Howlader N, Noone AM, Krapcho M, et al. (2013): SEER Cancer Statistics Review, 1975-2009 (Vintage 2009 Populations), National Cancer Institute. Bethesda. Accessed at http://seer. cancer.gov/csr/1975_2009_pops09 on 8 August 2013.

8. Egawa S, Takeda K, Fukuyama S, et al. (2004): Clinicopathological Aspects of Small Pancreatic Cancer. Pancreas 28: 235-240.

9. Ariyama J, Suyama M, Ogawa K, Ikarai T (1986): Screening of pancreatic neoplasms and diagnostic rate of small pancreatic neoplasns. Nihon Rinsho 44: 1729-1734.

10. Winter JM, Cameron JL, Campbell KA, et al. (2006): 1423 pancreaticoduodenectomies for pancreatic cancer: a single institution experience. J Gastrointest Surg 10: 1199-1211.

11. Artinyan A, Anaya DA, McKenzie S, et al. (2011): Neoadjuvant therapy is associated with improved survival in resectable pancreatic adenocarcinoma. Cancer 117: 2044-2049.

12. Xu CP, Xue XJ, Liang N, et al. (2014): Effect of chemoradiotherapy and neoadjuvant chemoradiotherapy in resectable pancreatic cancer: a systematic review and metaanalysis. J Cancer Res Clin Oncol 140: 549-559.

13. Conroy T, Desseigne F, Ychou M, et al. (2011): The Groupe Tumeurs Digestives of Unicancer and the PRODIGE Intergroup. FOLFIRINOX versus gemcitabine for metastatic pancreatic cancer. N Engl J Med 364: 1817-1825.

14. Von Hoff DD, Ervin T, Arena FP, et al. (2013): Increased survival in pancreatic cancer with nabpaclitaxel plus gemcitabine. N Engl J Med 369: 1691-1703.

15. Burris HA III, Moore MJ, Andersen J, et al. (1997): Improvements in survival and clinical benefit with gemcitabine as firstline therapy for patients with advanced pancreas cancer: a randomized trial. J Clin Oncol 15: 2403-2413.

16. Moore MJ, Goldstein D, Hamm J, et al. (2007): Erlotinib plus gemcitabine compared with gemcitabine alone in patients with advanced pancreatic cancer: a phase III trial of the National Cancer Institute of Canada Clinical Trials Group. J Clin Oncol 25: 1960-1966.

17. Costello E, Greenhalf W, Neoptolemos JP (2012): New biomarkers and targets in pancreatic cancer and their application to treatment. Nat Rev Gastroenterol Hepatol 9: 435-444.

18. Park MJ, Kim YK, Choi SY, et al. (2014): Preoperative detection of small pancreatic carcinoma: value of adding diffusion-weighted imaging to conventional MR imaging for improving confidence level. Radiology 273: 433-443.

19. Freeny PC, Saunders MD (2014): Moving beyond Morphology: New Insights into the Characterization and Management of Cystic Pancreatic Lesions. Radiology 272: 345-363.

20. Jenssen C, Kahlb S (2015): Management of Incidental Pancreatic Cystic Lesions. Viszeralmedizin 31: 14-24.

21. Andrén-Sandberg A (2011): Complications of pancreatic surgery. N Am J Med Sci 3: 531-535.

22. Ho C-K, Kleeff J, Friess H, Büchler MW (2005): Complications of pancreatic surgery. HPB (Oxford) 7: 99-108.

23. Perumal S, Palaniappan R, Pillai SA, et al. (2013): Predictors of malignancy in chronic calcific pancreatitis with head mass. World J Gastrointest Surg 5: 97-103.

24. Hewitt MJ, McPhail MJ, Possamai L, et al. (2012): EUS-guided FNA for diagnosis of solid pancreatic neoplasms: a meta-analysis. Gastrointest Endosc 75: 319-331.

25. Iglesias-Garcia J, Lindkvist B, Larino-Noia J, Dominguez-Munoz JE (2012): The role of EUS in relation to other imaging modalities in the differential diagnosis between mass forming chronic pancreatitis, autoimmune pancreatitis and ductal pancreatic adenocarcinoma. Rev Esp Enferm Dig 104: 315-321.

26. Chang J, Schomer D, Dragovich T (2015): Anatomical, Physiological, and Molecular Imaging for Pancreatic Cancer: Current Clinical Use and Future Implications. Biomed Res Int 2015: 1-10.

27. Cooper CL, O’Toole SA, Kench JG (2013): Classification, morphology and molecular pathology of premalignant lesions of the pancreas. Pathology 45: 286-304.

28. Hruban RH, Maitra A, Goggins M (2008): Update on pancreatic intraepithelial neoplasia. Int J Clin Exp Pathol 1: 306-316.

29. Tanno S, Nakano Y, Koizumi K, et al. (2010): Pancreatic ductal adenocarcinomas in long-term follow-up patients with branch duct intraductal papillary mucinous neoplasms. Pancreas 39: 36-40.

30. Ohtsuka T, Tanaka M (2014): Pancreatic Ductal Adenocarcinoma Concomitant with Intraductal Papillary Mucinous Neoplasm of the Pancreas: Clinical and Molecular Aspects and an Approach to Early Diagnosis. Pancreapedia: Exocrine Pancreas Knowledge Base, Version 1.0, 2014.

31. Klöppel G, Basturk O, Schlitter AM, et al. (2014): Intraductal neoplasms of pancreas. Semin Diagn Patho 31: 452-466.

32. Feldmann G, Beaty R, Hruban RH, Maitra A (2007): Molecular genetics of pancreatic intraepithelial neoplasia. J Hepatobiliary Pancreat Surg 14: 224-232.

33. Macgregor-Das AM, Iacobuzio-Donahue CA (2013): Molecular pathways in pancreatic carcinogenesis. J Surg Oncol 107: $8-14$.

34. Canto MI, Goggins M, Hruban RH, et al. (2006): Screening for early pancreatic neoplasia in high-risk individuals: a prospective controlled study. Clin Gastroenterol Hepatol 4: 766-781.

35. Brune K, Abe T, Canto M, et al. (2006): Multifocal neoplastic precursor lesions associated with lobular atrophy of the pancreas in patients having a strong family history of pancreatic cancer. Am J Surg Pathol 30: 1067-1076.

36. Dexler SK, Foxlwell BM (2010): The role of toll-like receptors in chronic inflammation. Int J Biochem Cell Biol 42: 506-518.

37. Fischer M, Ehlers M (2008): Toll-like receptors in autoimmunity. Ann N Y Acad Sci 143: 21-34.

38. Takeuchi O, Akira S (2010): Pattern recognition receptors and inflammation. Cell 140: 805-820.

39. Rakoff-Nahoum S, Medzitov R (2009): Toll-like receptors and cancer. Nat Rev Cancer 9: 57-63.

40. Chung JY, Park YC, Ye H, Wu H (2002): All TRAFs are not created equal: common and distinct molecular mechanisms of TRAF-mediated signal transduction. J Cell Sci 115: 679-688.

41. Tseng PH, Matsuzawa A, Zhang W, et al. (2010): Different modes of ubiquitination of adaptor TRAF3 selectively activate the expression of type I interferons and proinflammatory cytokines. Nat Immunol 11: 70-75.

42. Park JS, Svetkauskaite D, He Q, et al. (2004): Involvement of toll-like receptors 2 and 4 in cellular activation by high mobility group box 1 protein. J Biol Chem 279: 7370-7377.

43. Bustin M (1999): Regulation of DNA-dependent activities by the functional motifs of the high-mobility-group chromosomal proteins. Mol Cell Biol 19: 5237-5246.

44. Wang H, Yang H, Czura CJ, et al. (2001): HMGB1 as a late mediator of lethal systemic inflammation. Am J Respir Crit Care Med 164: 1768-1773.

45. El Gazzar M (2007): HMGB1 modulates inflammatory responses in LPS-activated macrophages. Inflamm Res 56 : 162-167. 
46. Fukata M, Chen A, Vamadevan AS, et al. (2007): Toll-like receptor- 4 promotes the development of colitis-associated colorectal tumors. Gastroenterology 133: 1869-1881.

47. Goto Y, Arigami T, Kitago M, et al. (2008): Activation of Tolllike receptors 2, 3, and 4 on human melanoma cells induces inflammatory factors. Mol Cancer Ther 7: 3642-3653.

48. He W, Liu Q, Wang L, et al. (2007): TLR4 signaling promotes immune escape of human lung cancer cells by inducing immunosuppressive cytokines and apoptosis resistance. Mol Immunol 44: 2850-2859.

49. Ilvesaro JM, Merrell MA, Swain TM, et al. (2007): Toll like receptor-9 agonists stimulate prostate cancer invasion in vitro. Prostate 67: 774-781.

50. Kelly MG, Alvero AB, Chen R, et al. (2006): TLR-4 signaling promotes tumor growth and paclitaxel chemoresistance in ovarian cancer. Cancer Res 66: 3859-3868.

51. Ochi A, Graffeo CS, Zambirinis CP, et al. (2012): Toll-like receptor 7 regulates pancreatic carcinogenesis in mice and humans.J Clin Invest 122: 4118-4129.

52. Tsujimoto H, Ono S, Majima T, et al. (2005):Neutrophil elastase, MIP-2, and TLR-4 Expression During Human and Experimental Sepsis. Shock 23: 39-44.

53. Schaaf B, Luitjens K, Goldmann T, et al. (2009): Mortality in human sepsis is associated with downregulation of Toll-like receptor 2 and CD14 expression on blood monocytes. Diagn Pathol 4: 12-19.

54. Subramanian S, Tus K, Li Q-Z, et al. (2006): A Tlr7 translocation accelerates systemic autoimmunity in murine lupus. Proc Natl Acad Sci U S A 103: 9970-9975.

55. Roelofs MF, Wenink MH, Brentano F, et al. (2009): I interferons might form the link between Toll-like receptor (TLR) 3/7 and TLR4-mediated synovial inflammation in rheumatoid arthritis (RA). Ann Rheum Dis 68: 1486-1493.

56. Devaraj S, Dasu MR, Rockwood J, et al. (2008): Increased Toll-like receptor (TLR) 2 and TLR4 expression in monocytes from patients with type 1 diabetes: further evidence of a proinflammatory state. J Clin Endocrinol Metab 93: 578-583.

57. Yu L, Chen S (2008): Toll-like receptors expressed in tumor cells: target for therapy. Cancer Immunol Immunother 57: 1271-1278.

58. Zhang JJ, Wu HS, Wang L, et al. (2010): Expression and significance of TLR4 and HIF-1 $\alpha$ in pancreatic ductal adenocarcinoma. World J Gastroenterol 16: 2881-2888.

59. Morse DL, Balagurunathan Y, Hostetter G, et al. (2010): Identification of novel pancreatic adenocarcinoma cell-surface targets by gene expression profiling and tissue microarray. Biochem Pharmacol 80: 748-754.

60. Rosenberg JS, Singh S, Raul S, et al. (2011): Pancreatic cancer screening by TLR phenotyping. Cancer Res 71 Suppl 8: Abstract 894.

61. Huang B, Zhao J, Li H, et al. (2005): Toll-like receptors on tumor cells facilitate evasion of immune surveillance. Cancer Res 65: 5009-5014.

62. Sato Y, Goto Y, Narita N, Hoon DS (2009): Cancer cells expressing Toll-like receptors and the tumor microenvironment. Cancer Microenviron 2: 205-214.

63. Zhou M, McFarland-Mancini MM, Funk HM, et al. (2009): Toll-like receptor expression in normal ovary and ovarian tumors. Cancer Immunol Immunother 58: 1375-1385.

64. Wang EL, Qian ZR, Nakasono M, et al. (2010): High expression of Toll-like receptor 4/myeloid differentiation factor 88 signals correlates with poor prognosis in colorectal cancer. $\mathrm{Br}$ J Cancer 102: 908-915.
65. Basith S, Manavalan B, Yoo TH, et al. (2012): Roles of tolllike receptors in cancer: a double-edged sword for defense and offense. Arch Pharm Res 35: 1297-1316.

66. Ochi A, Nguyen AH, Bedrosian AS, et al. (2012): MyD88 inhibition amplifies dendritic cell capacity to promote pancreatic carcinogenesis via Th2 cells. J Exp Med 209: 1671-1687.

67. Del Pozo JL (2010): Primers on molecular pathways: lipopolysaccharide signaling-potential role in pancreatitis and pancreatic cancer. Pancreatology 10: 114-118.

68. Bloomston M, Zervos EE, Rosemurgy AS $2^{\text {nd }}$ (2002): Matrix metalloproteinases and their role in pancreatic cancer: a review of preclinical studies and clinical trials. Ann Surg Oncol 9: 668674.

69. Liu CY, Xu JY, Shi XY, et al. (2013): M2-polarized tumor-associated macrophages promoted epithelial-mesenchymal transition in pancreatic cancer cells, partially through TLR4/IL-10 signaling pathway. Lab Invest 93: 844-854.

70. Zambirinis CP, Ochi A, Barilla R, et al. (2013): Induction of TRIF-or MYD88-dependent pathways perturbs cell cycle regulation in pancreatic cancer. Cell Cycle 12: 1153-1154.

71. De Monte L, Reni M, Tassi E, et al. (2011): Intratumor T helper type 2 cell infiltrate correlates with cancer-associated fibroblast thymic stromal lymphopoietin production and reduced survival in pancreatic cancer. J Exp Med 208: 469-478.

72. Ikebe M, Kitaura Y, Nakamura M, et al. (2009): Lipopolysaccharide (LPS) increases the invasive ability of pancreatic cancer cells through the TLR4/MyD88 signaling pathway. J Surg Oncol 100: 725-731.

73. Vonlaufen A, Xu Z, Daniel B, et al. (2007): Bacterial endotoxin: a trigger factor for alcoholic pancreatitis? Evidence from a novel, physiologically relevant animal model. Gastroenterology 133: 1293-1303.

74. Wang JH, Manning BJ, Wu QD, et al. (2003): Endotoxin/lipopolysaccharide activates NF- $\mathrm{KB}$ and enhances tumor cell adhesion and invasion through a $\beta-1$ integrin-dependent mechanism. J Immunol 170: 795-804.

75. Onier N, Hilpert S, Arnould L, et al. (1999): Cure of colon cancer metastasis in rats with the new lipid A OM 174. Apoptosis of tumor cells and immunization of rats. Clin Exp Metastasis 17: 299-306.

76. Reisser D, Pance A, Jeannin JF (2002): Mechanisms of antitumoral effect of lipid A. Bioessays 24: 284-289.

77. Isambert N, Fumoleau P, Paul C, et al. (2013): Phase I study of OM-174, a lipid A analogue, with assessment of immunological response, in patients with refractory solid tumors. BMC Cancer 13: $172-182$.

78. Fan P, Zhang JJ, Wang B, et al. (2012): Hypoxia-inducible factor-1 upregulates the expression of Toll-like receptor 4 in pancreatic cancer cells under hypoxic conditions. Pancreatology 12: $170-178$.

79. Chen K, Huang J, Gong W, et al. (2007): Toll-like receptors in inflammation, infection and cancer. Int Immunopharmacol 7: $1271-1285$.

80. Cheng N, He R, Tian J, et al. (2008): Cutting edge: TLR2 is a functional receptor for acute-phase serum amyloid A. J Immunol 181: 22-26.

81. Kanzler H, Barrat FJ, Hessel EM, Coffman RL (2007): Therapeutic targeting of innate immunity with Toll-like receptor agonists and antagonists. Nat Med 13: 552-559.

82. Zuany-Amorim C, Hastewell J, Walker C (2002): Toll-like receptors as potential therapeutic targets for multiple diseases. Nat Rev Drug Discov 1: 797-807. 
83. Schneider C, Schmidt T, Ziske C, et al. (2004): Tumor suppression induced by the macrophage activating lipopeptide MALP2 in an ultrasound guided pancreatic carcinoma mouse model. Gut 53: 355-361.

84. Schmidt J, Welsch T, Jäger D, et al. (2007): Intratumoral injection of the toll-like receptor-2/6 agonist 'macrophage-activating lipopeptide-2' in patients with pancreatic carcinoma: a phase I/II trial. Br J Cancer 97: 598-604.

85. Rosendahl AH, Sun C, Wu D, Andersson R (2012): Polysaccharide-K (PSK) increases p21(WAF/Cip1) and promotes apoptosis in pancreatic cancer cells. Pancreatology 12: 467-474.

86. Shime H, Matsumoto M, Seya T: The role of innate immune signaling in regulation of tumor-associated myeloid cells. In: Inflammation and Immunity in Cancer. Seya T (eds.). Japan: Springer 2015; 25-48.

87. Park HD, Lee Y, Oh YK, et al. (2011): Pancreatic adenocarcinoma upregulated factor promotes metastasis by regulating TLR/CXCR4 activation. Oncogene 30: 201-211.

88. Kim SA, Lee Y, Jung DE, et al. (2009): Pancreatic adenocarcinoma up-regulated factor (PAUF), a novel up-regulated secretory protein in pancreatic ductal adenocarcinoma. Cancer Sci 100: 828-836.

89. Kang TH, KimYS, Kim S, et al. (2015): Pancreatic adenocarcinoma upregulated factor serves as adjuvant by activating dendritic cells through stimulation of TLR4. Oncotarget 6: 27751-27762.

90. Kim SK, Song SY,Kim S, et al. (2014): Association of pancreatic adenocarcinoma up-regulated factor expression in ovarian mucinous adenocarcinoma with poor prognosis. Int J Clin Exp Pathol 7: 5103-5110.

91. Huynh AS, Chung WJ, Cho HI, et al. (2012): Novel Toll-like Receptor 2 Ligands for Targeted Pancreatic Cancer Imaging and Immunotherapy. J Med Chem 55: 9751-9762.

92. Zom GG, Khan S, Britten CM, et al. (2014): Efficient induction of antitumor immunity by synthetic toll-like receptor ligand-peptide conjugates. Cancer Immunol Res 2: 756-764.

93. Hemmi H, Takeuchi O, Kawai T, et al. (2000): Toll-like receptor recognizes bacterial DNA. Nature 408: 740-745.

94. Polvani S, Tarocchi M, Tempesti S, et al. (2016): Peroxisome proliferator activated receptors at the crossroad of obesity, diabetes, and pancreatic cancer. World J Gastroenterol 22: 24412459.

95. Adams S (2009): Toll-like receptor agonists in cancer therapy. Immunotherapy 1: 949-964.

96. Shojaei H, Oberg HH, Juricke M, et al. (2009): Toll-like receptors 3 and 7 agonists enhance tumor cell lysis by human gammadelta T cells. Cancer Res 69: 8710-8717.

97. Gonnermann D, Oberg HH, Kellner C, et al. (2015): Resistance of cyclooxygenase- 2 expressing pancreatic ductal adenocarcinoma cells against $\gamma \delta$ T cell cytotoxicity. Oncoimmunology 4 : e988460.

98. Grimmig T, Matthes N, Hoeland K, et al. (2015): TLR7 and TLR8 expression increases tumor cell proliferation and promotes chemoresistance in human pancreatic cancer. Int $\mathrm{J}$ Oncol 47: 857-866.

99. Vaz J, Akbarshahi H, Andersson R (2013): Controversial role of toll-like receptors in acute pancreatitis. World J Gastroenterol 19: 616-630.

100. Zeng YJ, Song JM, Li Y, et al. (2008): Toll-like receptor 9 is expressed in rat pancreas and is involved in cerulein-induced pancreatitis. Pancreas 36: 212-214.
101. Wu HQ, Wang B, Zhu SK, et al. (2011): Effects of CPG ODN on biological behavior of PANC-1 and expression of TLR9 in pancreatic cancer. World J Gastroenterol 17: 996-1003.

102. Li Y, Zhou ZG, Xia QJ, et al. (2005): Toll-like receptor 4 detected in exocrine pancreas and the change of expression in cerulein-induced pancreatitis. Pancreas 30: 375-381.

103. Kemp TJ, Ludwig AT, Earel JK, et al. (2005): Neutrophil stimulation with Mycobacterium bovis bacillus Calmette-Guerin (BCG) results in release of functional TRAIL/Apo-2L. Blood 106: 3474-3482.

104. Manegold C, Gravenor D, Woytowitz D, et al. (2008): Randomized phase II trial of a toll-like receptor 9 agonist oligodeoxynucleotide, PF-3512676, in combination with first-line taxane plus platinum chemotherapy for advanced-stage nonsmall-cell lung cancer. J Clin Oncol 26: 3979-3986.

105. Mauri D, Kamposioras K, Tsali L, et al. (2010): Overall survival benefit for weekly vs.three-weekly taxanes regimens in advanced brest cancer: A meta-analysis. Cancer Treat Rev 36: 69-74.

106. Garay RP, Viens P, Bauer J, et al. (2007): Cancer relapse underchemotherapy: Why TLR2/4 receptor agonists can help. Eur J Pharmacol 563: 1-17.

107. Jacobs C, Duewell P, Heckelsmiller K, et al. (2011): An ISCOM vaccine combined with a TLR9 agonist breaks immune evasion mediated by regulatory $\mathrm{T}$ cells in an orthotopic model of pancreatic carcinoma. Int J Cancer 128: 897-907.

108. Bauer C, Sterzik A, Bauernfeind F, et al. (2014): Concomitant gemcitabine therapy negatively affects DC vaccine-induced CD8(+) T-cell and B-cell responses but improves clinical efficacy in a murine pancreatic carcinoma model. Cancer Immunol Immunother 63: 321-333.

109. Friess H, Wang L, Zhu Z, et al. (1999): Growth factor receptors are differentially expressed in cancers of the papilla of Vater and pancreas. Ann Surg 230: 767-774.

110. Rosa R, Melisi D, Damiano V, et al. (2011): Toll-like receptor 9 agonist IMO cooperates with cetuximab in K-ras mutant colorectal and pancreatic cancers. Clin Cancer Res 17: 6531-6541.

111. Pratesi G, Petrangolini G, Tortoreto M, et al. (2005): Therapeutic synergism of gemcitabine and CpGO ligodeoxynucleotides in an orthotopic human pancreatic carcinoma xenograft. Cancer Res 65: 6388-6393.

112. Furrie E, Macfarlane S, Thomson G, Macfarlane GT (2005): Toll-like receptors-2, -3 and -4 expression patterns on human colon and their regulation by mucosal-associated bacteria. Immunology 115: 565-574.

113. Nishimura M, Naito S (2005): Tissue-specific mRNA expression profiles of human toll-like receptors and related genes. Biol Pharm Bull 28: 886-892.

114. Yoneda K, Sugimoto K, Shiraki K, et al. (2008): Dual topology of functional Toll-like receptor 3 expression in human hepatocellular carcinoma: differential signaling mechanisms of TLR3-induced NF-kappaB activation and apoptosis. Int J Oncol 33: 929-936.

115. Szczepanski M, Stelmachowska M, Stryczyński L, et al. (2007): Assessment of expression of toll-like receptors 2, 3 and 4 in laryngeal carcinoma. Eur Arch Otorhinolaryngol 264: 525-530.

116. Le UM, Yanasarn N, Lohr CV, et al. (2008): Tumor chemo-immunotherapy using gemcitabine and a synthetic dsRNA. Cancer Biol Ther 7: 440-447.

117. Salaun B, Lebecque S, Matikainen S, et al. (2007): Toll-like receptor 3 expressed by melanoma cells as a target for therapy? Clin Cancer Res 13: 4565-4574. 
118. Salaun B, Coste I, Rissoan MC, et al. (2006): TLR3 can directly trigger apoptosis in human cancer cells. J Immunol 176: 4894-4901.

119. Laplanche A, Alzieu L, Delozier T, et al. (2000): Polyadenylic-polyuridylic acid plus locoregional radiotherapy versus chemotherapy with CMF in operable breast cancer: a 14 year follow-up analysis of a randomized trial of the Federation Nationale des Centres de Lutte contre le Cancer (FNCLCC). Breast Cancer Res Treat 64: 189-191.

120. Schwartz AL, Malgor R, Dickerson E, et al. (2009): Phenylmethimazole decreases Toll-like receptor 3 and noncanonical Wnt5a expression in pancreatic cancer and melanoma together with tumor cell growth and migration. Clin Cancer Res 15: 4114-4122.

121. Taura M, Fukuda R, Suico MA, et al. (2010): TLR3 induction by anticancer drugs potentiates poly I:C-induced tumor cell apoptosis. Cancer Sci 101: 1610-1617.

122. Tissari J, Sirén J, Meri S, et al. (2005): IFN-alpha enhances TLR3-mediated antiviral cytokine expression in human endothelial and epithelial cells by up-regulating TLR3 Expression. J Immunol 174: 4289-4294.

123. Kato K, Lillehoj EP, Kim KC (2014): MUC1 regulates epithelial inflammation and apoptosis by PolyI:C through inhibition of Toll/IL-1 receptor-domain-containing adapter-inducing IFN- $\beta$ (TRIF) recruitment to Toll-like receptor 3.Am J Respir Cell Mol Biol 51: 446-454.

124. Lan MS, Batra SK, Qi WN, et al. (1990): Cloning and sequencing of a human pancreatic tumor mucin cDNA. J Biol Chem 265: 15294-15299.

125. Lau SK, Weiss LM, Chu PG (2004): Differential expression of MUC1, MUC2, and MUC5AC in carcinomas of various sites: an immunohistochemical study. Am J Clin Pathol 122: 61-69.

126. Yamada N, Nishida Y, Tsutsumida H, et al. (2008): MUC1 expression is regulated by DNA methylation and histone $\mathrm{H} 3$ lysine 9 modification in cancer cells. Cancer Res 68: 2708-2716.

127. Luttges J, Feyerabend B, Buchelt T, et al. (2002): The mucin profile of noninvasive and invasive mucinous cystic neoplasms of the pancreas. Am J Surg Pathol 26: 466-471.

128. Seshacharyulu P, Ponnusamy MP, Rachagani S, et al. (2015): Targeting EGF-receptor(s) - STAT1 axis attenuates tumor growth and metastasis through downregulation of MUC4 mucin in human pancreatic cancer. Oncotarget 6: 5164-5181.

129. Burdelya LG, Krivokrysenko VI, Tallant TC, et al. (2008): An agonist of toll-like receptor 5 has radioprotective activity in mouse and primate models. Science 320: 226-230.

130. Soto LJ ${ }^{3 r d}$, Sorenson BS, Kim AS, et al. (2003): Attenuated Salmonella typhimurium prevents the establishment of unresectable hepatic metastases and improves survival in a murine model. J Pediatr Surg 38: 1075-1079.

131. Yam C, Zhao M, Hayashi K, et al. (2010): Monotherapy with a tumor-targeting mutant of S. typhimurium inhibits liver metastasis in a mouse model of pancreatic cancer. J Surg Res 164: 248-255.

132. Burdelya LG, Bracketta CM, Kojouharova B, et al. (2013): Central role of liver in anticancer and radioprotective activities of Toll-like receptor 5 agonist. Proc Natl Acad Science U S A 110: E1857-E1866.

133. Cai Z, Sanchez A, Shi Z, et al. (2011): http://cancerres.aacrjournals.org/search?author1=Dekai+Zhang\&sortspec=date\&submit=SubmitActivation of Toll-like Receptor 5 on Breast Cancer Cells by Flagellin Suppresses Cell Proliferation and Tumor Growth. Cancer Res 71: 2466-2475.
134. Rhee SH, Im E, Pothoulakis C (2008): Toll-like receptor 5 engagement modulates tumor development and growth in a mouse xenograft model of human colon cancer. Gastroenterology135: 518-528

135. Schmausser B, Andrulis M, Endrich S, et al. (2005): Toll-like receptors TLR4, TLR5 and TLR9 on gastric carcinoma cells: an implication for interaction with Helicobacter pylori. Int J Med Microbiol 295: 179-185.

136. Zeng H-M, Pan K-F, Zhang Y, et al. (2011): Genetic Variants of Toll-Like Receptor 2 and 5, Helicobacter Pylori Infection, and Risk of Gastric Cancer and Its Precursors in a Chinese Population. Cancer Epidemiol Biomarkers Prev 20: 2594-2602.

137. Chung HW, Lim JB, Jang S, et al. (2012): Serum high mobility group box-1 is a powerful diagnostic and prognostic biomarker for Pancreatic Ductal Adenocarcinoma. Cancer Sci 103: 17141721.

138. Kang R, Tang D, Schapiro NE, et al. (2010): The receptor for advanced glycation end products (RAGE) sustains autophagy and limits apoptosis, promoting pancreatic tumor cell survival. Cell Death Differ 17: 666-676.

139. Ellerman JE, Brown CK, de Vera M, et al. (2007): Masquerader: high mobility group box-1 and cancer. Clin Cancer Res 13: $2836-2848$

140. Chung HW, Lee SG, Kim H, et al. (2009): Serum high mobility group box-1 (HMGB1) is closely associated with the clinical and pathologic features of gastric cancer. J Transl Med 7: 3849.

141. Liang XY, Li QQ, Zhang ZL, et al. (2014): High Mobility Group Box 1 (HMGB1) is Associated with Progression and Poor Prognosis in Pancreatic Cancer. J Gastroint Dig Syst 4: 190.

142. Lotze MT, Tracey KJ (2005): High-mobility group box 1 protein (HMGB1): nuclear weapon in the immune arsenal. Nat Rev Immunol 5: 331-342.

143. Kang R, Tang D, Schapiro NE, et al. (2014): The HMGB1/ RAGE inflammatory pathway promotes pancreatic tumor growth by regulating mitochondrial bioenergetics. Oncogene 33: 567-577.

144. Wang W, Abbruzzese JL, Evans DB, et al. (1999): The nuclear factor-nB RelA transcription factor is constitutively activated in human pancreatic adenocarcinoma cells. Clin Cancer Res 5: 119-127.

145. Starczynowski DT, Lockwood WW, Deléhouzée S, et al. (2011): TRAF6 is an amplified Oncogene bridging the RAS and NF-kB pathways in human lung cancer. J Clin Invest 121: 4095-4105.

146. Sun H, Li XB, Meng Y, et al. (2013): TRAF6 upregulates expression of HIF-1alpha and promotes tumor angiogenesis. Cancer Res 73: 4950-4959.

147. Erkan M, Reiser-Erkan C, Michalski CW, et al. (2009): Cancer-stellate cell interactions perpetuate the hypoxia-fibrosis cycle in pancreatic ductal adenocarcinoma. Neoplasia 11: 497508.

148. Rong Y, Wang D, Wu W, et al. (2014): TRAF6 is over-expressed in pancreatic cancer and promotes the tumorigenicity of pancreatic cancer cells. Med Oncol 31: 260.

149. Chiu HW, Lin SW, Lin LC, et al. (2015): Synergistic antitumor effects of radiation and proteasome inhibitor treatment in pancreatic cancer through the induction of autophagy and the downregulation of TRAF6. Cancer Lett 365: 229-239.

150. Słotwiński R, Dąbrowska A, Lech G, et al. (2014): Gene expression disorders of innate antibacterial signaling pathway in 
pancreatic cancer patients: implications for leukocyte dysfunction and tumor progression. Cent Eur J Immunol 39: 498-507.

151. Kędziora S, Słotwiński R, Dąbrowska A, et al. (2012): Glutamine abolishes the TLR4 gene overexpression in pancreatic cancer patients: a preliminary study. Cent Eur J Immunol 37: 350-354.

152. Kessel A, Toubi E, Pavlotzky E, et al. (2008): Treatment with glutamine is associated with down-regulation of Toll-like receptor- 4 and myeloid differentiation factor 88 expression and decrease in intestinal mucosal injury caused by lipopolysaccharide endotoxemia in a rat. Clin Exp Immunol 151: 341-347.

153. Lee JY, Plakidas A, Lee WH, et al. (2003): Differential modulation of Toll-like receptors by fatty acids: preferential inhibition by n-3 polyunsaturated fatty acids. J Lipid Res 44: 479-486.

154. Hsu RY, Chan CH, Spicer JD, et al. (2011): LPS-Induced TLR4 Signaling in Human Colorectal Cancer Cells Increases $\beta 1$ Integrin-Mediated Cell Adhesion and Liver Metastasis. Cancer Res 71: 1989-1998.

155. Fukui M, Kang KS, Okada K, Zhu BT (2013): EPA, an omega-3 fatty acid, induces apoptosis in human pancreatic cancer cells: role of ROS accumulation, caspase- 8 activation, and autophagy induction. J Cell Biochem 114: 192-203.

156. Shirota T, Haji S, Yamasaki M, et al. (2005): Apoptosis in human pancreatic cancer cells induced by eicosapentaenoic acid. Nutrition 21: 1010-1017.

157. Dai J, Shen J, Pan W, et al. (2013): Effects of polyunsaturated fatty acids on the growth of gastric cancer cells in vitro. Lipids Health Dis 12: 71.

158. D'Eliseo D, Velotti F (2016): Omega-3 fatty acids and cancer cell cytotoxicity: implications for multi-targeted cancer therapy. J Clin Med 5: pii: E15.

159. Arshad A, Isherwood J, Mann C, et al. (2015): Intravenous $\omega-3$ fatty acids plus gemcitabine. Potential to improve response and quality of life in advanced pancreatic cancer. JPEN J Parenter Enteral Nutrpii: 0148607115595221.

160. Liu HQ, Qiu Y, Mu Y, et al. (2013): A high ratio of dietary n-3/n-6 polyunsaturated fatty acids improves obesity-linked inflammation and insulin resistance through suppressing activation of TLR4 in SD rat. Nutr Res 33: 849-858.

161. Wendel M, Heller AR (2009): Anticancer actions of omega-3 fatty acids - current state and future perspectives. Anticancer Agents Med Chem 9: 457-470.

162. Yang P, Jiang Y, Fischer SM (2014): Prostaglandin E3 metabolism and cancer. Cancer Lett 348: 1-11.

163. Wang W, Zhu J, Lyu F, et al. (2014): $\omega-3$ polyunsaturated fatty acids-derived lipid metabolites on angiogenesis, inflammation and cancer. Prostaglandins Other Lipid Mediat 113-115: 13-20.

164. Mai CW, Kang YB, Pichika MR (2013): Should a Toll-like receptor 4 (TLR-4) agonist or antagonist be designed to treat cancer? TLR-4: its expression and effects in the ten most common cancers. Onco Targets Ther 6: 1573-1587.

165. Carneiro LA, Travassos LH, Philpott DJ (2004): Innate immune recognition of microbes through Nod1 and Nod2: implications for disease. Microbes Infect 6: 609-616.

166. Santoni M, Andrikou K, Sotte V, et al. (2015): Toll like receptors and pancreatic diseases: From a pathogenetic mechanism to a therapeutic target. Cancer Treat Rev 41: 569-576.

167. Sońdka Z, Tretyn A, Szeliga J, Jackowski M (2006): Involvement of leucine rich repeats (LRR) domain containing proteins in molecular mechanisms of innate immunity of plants and animals. Post Biol Kom 33: 635-656.
168. Chamaillard M, Hashimoto M, Horie Y et al. (2003): An essential role for Nod1 in host recognition of bacterial peptidoglycan containing diaminopimelic acid. Nat Immunol 4: 702-707.

169. Girardin SE, Boneca IG, Viala J, et al. (2003): Nod2 is a general sensor of peptidoglykan through muramyl dipeptide (MDP) detection. J Biol Chem 278: 8869-8872.

170. Lee JY, Hwang DH (2006): The modulation of inflammatory gene expression by lipids: mediation through Toll-like receptors. Mol Cells 21: 174-185.

171. Jiang W, Wang X, Zeng B, et al. (2013): Recognition of gut microbiota by NOD2 is essential for the homeostasis of intestinal intraepithelial lymphocytes. J Exp Med 210: 2465-2476.

172. Chen GY, Shaw MH, Redondo G, Núńez G (2008): The innate immune receptor Nod1 protects the intestine from inflammation-induced tumorigenesis. Cancer Res 68: 10060-10067.

173. Prajapati B, Jena PK, Rajput P, et al. (2014): Understanding and modulating the Toll like Receptors (TLRs) and NOD like Receptors (NLRs) cross talk in type 2 diabetes. Curr Diabetes Rev 10: 190-200.

174. Kurzawski G, Suchy J, Kładny J, et al. (2004): The NOD2 3020insC mutation and the risk of colorectal cancer. Cancer Res 64: 1604-1606.

175. Kutikhin AG (2011): Role of NOD1/CARD4 and NOD2/ CARD15 gene polymorphisms in cancer etiology.Hum Immunol 72: 955-968.

176. Liu J, He C, Xu Q, et al. (2014): NOD2 Polymorphisms Associated with Cancer Risk: A Meta-Analysis. PLoS One 9: e89340.

177. Li D, Duell EJ, Yu K, et al. (2012): Pathway analysis of genome-wide association study data highlights pancreatic development genes as susceptibility factors for pancreatic cancer. Carcinogenesis 33: 1384-1390.

178. Ino Y, Yamazaki-Itoh R, Shimada K, et al. (2013): Immune cell infiltration as an indicator of the immune microenvironment of pancreatic cancer. Br J Cancer 108: 914-923.

179. Gabitass RF, Annels NE, Stocken DD, et al. (2011): Elevated myeloid-derived suppressor cells in pancreatic, esophageal and gastric cancer are an independent prognostic factor and are associated with significant elevation of the Th2 cytokine interleukin-13. Cancer Immunol Immunother 60: 1419-1430.

180. Landskron G, De la Fuente M, Thuwajit P, et al. (2014): Chronic Inflammation and Cytokines in the Tumor Microenvironment. J Immunol Res 2014: 1-19.

181. Rauser S, Langer R, Tschernitz S, et al. (2010): High number of CD45RO+ tumor infiltratinglymphocytes is an independent prognostic factorin non-metastasized (stage I-IIA) esophagealadenocarcinoma. BMC Cancer 10: 608-617.

182. Arora A, Singh S, Bhatt AN, et al. (2015): Interplay between metabolism and oncogenic process: Role of microRNAs. Transl Oncogenomics 7: 11-27.

183. Son J, Lyssiotis CA, Ying H, et al. (2013): Glutamine supports pancreatic cancer growth through a KRAS-regulated metabolic pathway. Nature 496: 101-105.

184. Chakrabarti G, Moore ZR, Luo X, et al. (2015): Targeting glutamine metabolism sensitizes pancreatic cancer to PARP-driven metabolic catastrophe induced by ß-lapachone. Cancer Metab 3: 12 .

185. Hering J, Garrean S, Dekoj TR, et al. (2007): Inhibition of Proliferation by Omega- 3 Fatty Acids in Chemoresistant Pancreatic Cancer Cells. Ann Surg Oncol 14: 3620-3628.

186. Sun L, Chua CY, Tian W, et al. (2015): MicroRNA signaling pathway network in pancreatic ductal adenocarcinoma. J Genet Genomics 42: 563-577. 